\title{
Anthocyanin Effects in Reducing Platelet Hyperactivity and Thrombotic Risk in Type 2 Diabetes
}

\author{
Almottesembellah Gaiz ${ }^{1,2 *}$, Sapha Shibeeb ${ }^{1,3}$, Avinash Reddy Kundur ${ }^{1}$, Natalie Colson ${ }^{1}$, Anahita Aboonabi ${ }^{1}$, Josif Vidimce ${ }^{1}$ and \\ Indu Singh ${ }^{1}$ \\ ${ }^{1}$ School of Medical Science, Griffith University, Gold Coast Campus, Parkland Drive, Southport, Queensland 4222, Australia \\ ${ }^{2}$ National Centre of Hematology, Almustansiriyah University, Baghdad, Iraq \\ ${ }^{3}$ Department of Biomedical Science, College of Health Sciences, QU Health, Qatar University, Qatar
}

*Corresponding author: Almottesembellah Gaiz PhD., School of Medical Sciences, Griffith University, Gold Coast campus, Parkland Drive, Southport, Queensland 4222, Australia; E-mail: almotesem78@gmail.com; a.gaiz@griffithuni.edu.au

Received: April 24, 2021; Accepted: April 26, 2021; Published: May 1, 2021

\begin{abstract}
Background: Platelet hyperactivity has a crucial role in initiating vascular thrombosis and subsequent cardiovascular disease (CVD) in type 2 diabetes mellitus (T2DM). This study aims to assess the effect of anthocyanins on several risk markers of thrombosis in T2DM. Twenty-three patients with T2DM consumed $320 \mathrm{mg}$ of AC/day in the form of Medox ${ }^{\oplus}$ capsules for 28 days. Blood pressure and anthropometric measures were taken before and after the intervention period. Fasting blood samples were collected pre and post-intervention to perform different analyses. Analysis of platelet activation measured the platelet activation measured the expression of platelet surface marker. Surface markers included CD41a and P-selectin in adenosine diphosphate (ADP) stimulated platelets. Platelet aggregation, full blood examination, coagulation and biochemistry profile analyses were also evaluated pre and post-intervention.

Results: Flow cytometric analysis showed no effect of AC on the expression of P-selectin. There were significant reductions in ADP and collagenstimulated platelet aggregation. The hematologic measurements showed no impact of AC. Coagulation analysis demonstrated a non-significant change of prothrombin time, activated partial thromboplastin time, or fibrinogen level in the blood. This study showed a reduction of platelet aggregation and total serum cholesterol. These results suggest that AC positively impacts attenuating platelet function potential improvement in lipid profile, minimising thrombotic risk.
\end{abstract}

Keywords: anthocyanin, antiplatelet, platelet activation, diabetes mellitus type 2

\section{Introduction}

Hyperactivity of platelets, inflammation, and increased oxidative stress have a central role in the pathogenesis of several conditions, including, type 2 diabetes mellitus (T2DM), thrombosis, and cardiovascular disease (CVD) [1]. T2DM is associated with increased macro-vascular complications, which significantly elevate the risk of cardiovascular mortality among these individuals [2]. Platelets are enucleated blood cells that play a vital role in primary haemostasis. Platelet hyperactivity, in the presence of free radicals, can significantly accelerate the progression of atherosclerosis. Free radicals have a significant effect on developing oxidative stress before platelet hyperactivity [3]. For instance, impaired muscle glucose uptake, endothelial dysfunction, and lipid oxidation are predisposed by oxidative stress detected in disorders such as T2DM [4-6]. Platelet activation and coagulation exemplify a biological indicator to predict vascular events in the future [7]. Endothelial damage of the vascular wall or injury of atheromatous plaque is a primary step in plateletassociated thrombogenesis. Platelets stick to the site of endothelial injury and change their shape. Consequently, platelets undergo degranulation and activation process. Activation of platelets leads to fibrinogen binding to platelet receptors and finally, the formation of thrombus.

Aspirin is an antiplatelet drug that reduces platelet hyperactivity. Aspirin target the cyclooxygenase-2 (COX-2) pathway and inhibiting thromboxane A2 (TXA2) production. Although aspirin is still the first-line antiplatelet agent [8] used in the treatment of acute coronary syndromes (ACS), many studies have recently highlighted aspirin resistance $[9,10]$ and its side effects, especially in individuals with T2DM. With aspirin and clopidogrel, two anti-platelet therapies are the most widely used antiplatelet treatment to treat ACS $[8,11$, 12]. A plethora of studies has demonstrated the potential of plantbased antioxidants is not only inhibiting platelet activity but also in alleviating several risk factors that are associated with atherosclerosis and subsequent cardiovascular disease.

Several studies show the positive effects of consuming antioxidantrich diet, especially fruits and vegetables [13-15] in 2004, Hung and colleagues [16] conducted a cohort study recommending to consuming five or more servings of fruits and vegetables to lower CVD risk. Antioxidants reduce or suppress atherosclerotic progression and 
alleviate CVD development [16-18]. This anti-thrombotic potential of phytochemicals has encouraged nutraceutical industries to explore the use of natural antioxidants as a complementary therapy to the currently used anti-platelet treatment [7]. The effect of natural antioxidants such as anthocyanins to reduce platelet hyperactivity is due to blocking variable platelet receptors and inhibiting free radicals, which initiate platelet activity, thereby eliminates the risk of thrombus [19] [17, 18, 20-23] [7]. Although the effect of polyphenols on overall health is well documented, their actions on function and activity of platelets are changeable [7]. The variability in these findings increases the necessity to conduct a controlled and well-designed human intervention trial. Therefore, this study aims to examine the effect of pure Anthocyanins extracted from bilberries and blackcurrant (Medox') on platelet activity and thrombotic risk in patients with type $2 \mathrm{DM}$.

\section{Materials and methods}

\section{Participant recruitment and study design}

This study was approved by Griffith University Human Research Ethics Committee, Griffith University, Queensland, Australia (GU Ref No: MSC/07/14/HREC) and is registered with Australia and New Zealand Clinical Trials Registry (ACTRN12615000293561). Twentythree patients with T2DM were recruited from the general population after signing an informed consent before the commencement of the study. All the participants included in the study were carefully screened using health questionnaires and interviews to ensure that they were non-smoking and without bleeding disorders or liver disease. Participants taking an anti-inflammatory, anti-platelet agents or anticoagulants were not included in the study.

Before the commencement of the study, anthropometric measurements and blood pressure were checked. Also, baseline fasting blood samples were collected to determine the presence of any underlying health condition using results from full blood examination, platelet function assays, enzyme-linked immunosorbent assay (ELISA), coagulation and biochemistry profiles. Upon completion of the initial screening, the participants were requested to consume four AC extract caps (80mg per capsule) per day (320mg of AC extract per day) for 28 days. The current study has used this dosage based on previous studies that have demonstrated that AC supplementation at $320 \mathrm{mg}$ per day has significant beneficial effects on reducing risk factors of CVD such as inflammation, lipid profile and thrombosis [2426]. The four-week intervention was also finalised based on previous clinical trials conducted by our research team, that have shown that four week AC supplementation can significantly reduce platelet aggregation, activation and overall risk of thrombosis in individuals [27-29]. Anthropometric measurements and blood pressure were rechecked. Fasting blood samples were collected after the 28 days supplementation period. Adherence and compliance of AC capsule intake were monitored by checking the capsule strips returned by the participant after the supplementation and by personally interviewing them.

\section{Supplement Information}

Patients were assigned to twenty-eight days of AC intervention in capsule form at a daily dose of $320 \mathrm{mg}$ AC. AC supplement (Medox) is a hemicellulose capsule, which contains powder of anthocyanins extracted from Bilberries (Vaccinium myrtillus) and Black Currants (Ribes nigrum). Table 2 shows the relative amount of the primary $\mathrm{AC}$ components used in the intervention in each capsule. Each capsule contains $80 \mathrm{mg}$ of AC. More details of the relative amount of each $\mathrm{AC}$ compounds has been reported in the literature [25]. Patients were asked to consume four capsules per day (two capsules twice daily) after any two main meals of the day, i.e., breakfast, lunch or dinner. Participants were asked to maintain their habitual lifestyle and diet during the study period.

Table 1: Baseline demographic and anthropometric measures of 23 participants with T2DM.

\begin{tabular}{|l|c|}
\hline \multicolumn{1}{|c|}{ Parameter } & participant's value \\
\hline Age range (year) & $40-78$ \\
\hline Gender $($ male/female) & $16 / 7$ \\
\hline Weight $(\mathrm{kg})$ mean & 93.1 \\
\hline BMI $\left(\mathrm{kg} / \mathrm{m}^{2}\right)$ mean & 31.5 \\
\hline
\end{tabular}

Table 2: Anthocyanins components included in those capsuled which were used in the trial.

\begin{tabular}{|c|c|}
\hline Anthocyanin components & Percentage of ingredients \\
\hline $\begin{array}{l}\text {-Delphinidin 3-O- } \beta \text {-glucosides } \\
\text {-Delphinidin 3-O- } \beta \text {-galactosides } \\
\text {-Delphinidin 3-O- } \beta \text {-arabinosides }\end{array}$ & $59 \%$ \\
\hline $\begin{array}{l}\cdot \text { Cyanidin } 3 \text {-O- } \beta \text {-glucosides } \\
\text { •Cyanidin } 3-\mathrm{O}-\beta \text {-galactose } \\
\text { •Cyanidin } 3-\mathrm{O}-\beta \text {-arabinosides }\end{array}$ & $33 \%$ \\
\hline $\begin{array}{l}\text {-Malvidin 3-O- } \beta \text {-glucosides } \\
\text { - Malvidin 3-O- } \beta \text {-galactose } \\
\text {-Malvidin } 3 \text {-O- } \beta \text {-arabinosides }\end{array}$ & $3 \%$ \\
\hline $\begin{array}{l}\cdot \text { Peonidin } 3 \text {-O- } \beta \text {-glucosides } \\
\text { •Peonidin } 3 \text {-O- } \beta \text {-galactose } \\
\text { •Peonidin } 3-\mathrm{O}-\beta \text {-arabinosides }\end{array}$ & $2.5 \%$ \\
\hline $\begin{array}{l}\text {-Petunidin Petunidin } 3 \text {-O- } \beta \text {-glucosides } \\
\text {-Petunidin } 3 \text {-O- } \beta \text {-galactose } \\
\text {-Petunidin } 3 \text {-O- } \beta \text {-arabinosides }\end{array}$ & $2.5 \%$ \\
\hline Total & $100 \%$ \\
\hline
\end{tabular}

\section{Anthropometric measurements and blood pressure}

Weight and body mass index (BMI) were measured before and after the intervention period. Measurements were taken in light clothing, without shoes, watches, or other accessories. Height was determined to the closest $0.1 \mathrm{~cm}$ with a rod stadiometer (Surgical $\&$ Medical Products, Australia), anybody mass was measured using a BC- 601 digital body composition scale (Tanita Corporation, Australia). Body mass index (BMI) was calculated by dividing the body weight in kilograms by the height in metres and square. Systolic and diastolic blood pressure values were checked before and after the intervention period. The automatic device was used to monitor blood 
pressure reading. According to the device manual, all instructions were followed carefully during blood pressure measurement.

\section{Blood sample collection and full blood examination}

Fasting blood samples pre and post AC supplementation period were collected from the median cubital vein by a trained phlebotomist. The blood was then carefully aliquoted into one Ethylenediaminetetraacetic acid (EDTA; $1.8 \mathrm{mg} / \mathrm{ml}$ ) tube for FBE analysis, three tri-sodium citrate $(28.12 \mathrm{~g} / \mathrm{L})$ tubes for platelet function and coagulation studies and into one serum separation tubes (SST) for biochemical analysis. Beckman Coulter ACT ${ }^{\mathrm{TM}}$ 5Diff CP haematology analyzer (Coulter Corporation, Miami, Florida, USA) was used to perform FBE analysis.

\section{Platelet aggregation assay}

Platelet-rich plasma obtained (PRP) from whole blood collected into trisodium citrate anticoagulant tubes was used to perform platelet aggregation studies. PRP was extracted by the spinning of citrated whole blood at $180 \times \mathrm{g}$ for 10 minutes, followed by which platelet-poor plasma (PPP) was obtained by spinning the same tube at $2000 \times \mathrm{g}$ for 10 minutes. Platelet agonists stimulated platelet aggregation. The agonists were collagen $(2 \mu \mathrm{g} / \mathrm{mL}$ ), adenosine diphosphate (ADP; 5 $\mu \mathrm{M})$, Arachidonic Acid (AA) $(200 \mu \mathrm{g} / \mathrm{mL})$. Recording percentage aggregation was conducted for 6 minutes at a constant temperature of $37^{\circ} \mathrm{C}$. Platelet aggregation studies were performed using Helena AggRam Platelet Aggregometer (Helena laboratory, Beaumont Texas, USA). Platelet aggregation testing was completed within 2 hours of the blood collection.

\section{Evaluation of platelet activation}

Trisodium citrate anticoagulated whole blood was used to evaluate platelet activation. Monoclonal antibodies conjugated with specific fluorophores were used to identify and assess platelet activation, degranulation and formation of monocyte-platelet aggregates. CD 41a conjugated with Peridinin-chlorophyll-protein Complex CY5.5 (PerCP-CY5.5) was used to identify platelets. CD62P conjugated with allophycocyanin (APC) was used to quantify platelet degranulation. For analysis, citrated whole blood was diluted in 1:5 ratio with modified Tyrod's Buffer (MTB). A mixture of monoclonal antibodies was added to the diluted blood and incubated for 15 minutes at room temperature in the dark. $\mathrm{ADP}(5 \mu \mathrm{M})$ was added as an agonist to stimulate platelet activation, followed by which the samples were further incubated for 10 minutes. The samples were then fixed by adding $800 \mu \mathrm{l}$ of $10 \% \mathrm{RBC}$ lysing solution (BD Biosciences) and later analyzed on BD LSRFortessa flow cytometer.

\section{Coagulation profile}

Platelet-poor plasma (PPP) was used to perform coagulation assays. Coagulation testing was performed on the Stago R-Evolution Coagulation Analyserutilising the Stago STA-R software to run coagulation assays prothrombin time (PT), activated partial thromboplastin time (aPTT) and Fibrinogen concentration as per the manufacturer's instructions.

\section{Biochemistry profile}

Blood collected in serum separation tubes (SST) was centrifuged for 10 minutes at $2000 \mathrm{xg}$ at RT to extract serum for biochemical analysis. Serum levels of glucose, cholesterol, high-density lipoprotein (HDL), low-density lipoprotein (LDL), triglyceride (TG), and uric acid (UA) were determined using Integra Cobas 400 Biochemistry Analyser (Roche Diagnostics, Switzerland). Quality controls and calibrators were run before testing to ensure the accuracy of the analyser.

\section{Pro-inflammatory and adhesion markers}

Interleukin-8 (IL-8), vascular cell adhesion molecule (VCAM1) and intercellular adhesion molecule (ICAM-1) were detected using plasma samples collected into EDTA tubes. Human Magnetic Luminex Assays kit (R\&D), and Bio-Plex Analyser 200 (Bio-Rad, Texas, USA) were used to quantify each analyte based on superparamagnetic beads coated with analyte-specific antibodies. Beads recognizing different target analytes are mixed and incubated with the sample. Captured analytes are subsequently detected using a cocktail of biotinylated detection antibodies and a streptavidinphycoerythrin conjugate. A magnet in the analyserattracts and holds the super-paramagnetic microparticles in a monolayer. Two spectrally distinct Light Emitting Diodes (LEDs) illuminate the beads. One LED identifies the parameter that is being spotted and the second LED determines the magnitude of the PE-derived signal, which is in direct proportion to the amount of analyte bound. Each well is imaged with a CCD camera.

Samples were screened for the named pro-inflammatory biomarkers. Individual sets of samples from the same participants were run in the same assay kit. Plasma samples were thawed on ice and spun down at $14000 \times \mathrm{g}$ for 10 minutes at four ${ }^{\circ} \mathrm{C}$, before two-fold dilution and further processing. The assay was conducted according to the manufacturer's instruction. A further $1 / 10^{\text {th }}$ dilution of standard curves was considered to optimise the assay for low-level detection of analytes. As recommended by the manufacturer, a magnetic plate washer was used to guarantee higher yields of analytes.

\section{Statistical analysis}

Statistical analysis was performed using a Graph Pad Prism version 6 for windows. Paired t-test was used to analyse the data, and the values were expressed as mean \pm SME. The $p$ value $<0.05$ was considered statistically significant.

\section{Results}

\section{Full blood examination}

Table 3 shows data of ten hematological indices, including differential white blood cells count. There was no change of the blood count under the effect of AC. Most of the hematological indices were similarly affected under both treatments' conditions (pre and post). There were trends of increased or decreased blood cell counts after AC treatment, but they were non-significant. 
Table 3: Descriptive values of FBE parameters in 23 participants pre and post AC supplementation.

\begin{tabular}{|l|c|c|c|c|}
\hline $\begin{array}{c}\text { Haematological } \\
\text { Indices }\end{array}$ & $\begin{array}{c}\text { Pre-AC } \\
\text { Mean } \pm \text { SEM }\end{array}$ & $\begin{array}{c}\text { Post-AC } \\
\text { Mean } \pm \text { SEM }\end{array}$ & P value & $\begin{array}{c}\text { Reference } \\
\text { Range }\end{array}$ \\
\hline WBC $(\mathrm{X} \mathrm{10} / \mathrm{L})$ & $6.96 \pm 0.33$ & $7.16 \pm 0.31$ & 0.99 & $4.0-11.0$ \\
\hline RBC (X 10 $12 / \mathrm{L})$ & $5.22 \pm 0.15$ & $5.04 \pm 0.11$ & 0.91 & $3.8-6.5$ \\
\hline HGB (g/L) & $145.63 \pm 2.70$ & $143.38 \pm 3.27$ & 0.98 & $120-180$ \\
\hline HCT (\%) & $0.44 \pm 0.01$ & $0.43 \pm 0.01$ & 0.95 & $0.36-0.54$ \\
\hline MCV (fL) & $85.90 \pm 1.65$ & $86.04 \pm 1.015$ & 0.99 & $80-100$ \\
\hline MCH (pg) & $28.07 \pm 0.52$ & $28.37 \pm 0.38$ & 0.97 & $27-31$ \\
\hline MCHC (g/L) & $327.063 \pm 4.28$ & $330.15 \pm 2.99$ & 0.94 & $320-360$ \\
\hline RDW (\%) & $12.88 \pm 0.37$ & $12.45 \pm 0.29$ & 0.79 & $11.0-15.0$ \\
\hline PLT (X 10 $/ \mathrm{L})$ & $250.45 \pm 14.52$ & $271.51 \pm 15.23$ & 0.68 & $150-400$ \\
\hline MPV (fL) & $8.92 \pm 0.18$ & $8.80 \pm 0.14$ & 0.94 & $6.0-10.0$ \\
\hline
\end{tabular}

Values are represented as mean \pm SEM. No significant difference in FBE parameters was observed pre and post AC supplementation. Abbreviations: AC, anthocyanin; WBC, white blood cell; RBC, red blood cell; HGB, Haemoglobin; MCV, mean cell volume; $\mathrm{MCH}$, mean cell haemoglobin; $\mathrm{MCHC}$, mean corpuscular haemoglobin concentration; RDW, red cell distribution width; PLT, platelet; MPV, mean platelet volume.

\section{Anthropometric measurements}

The post-intervention measurement did not show any significant changes in the anthropometric data, including BMI and body weight, of participants, as shown in figure 1.
Wt

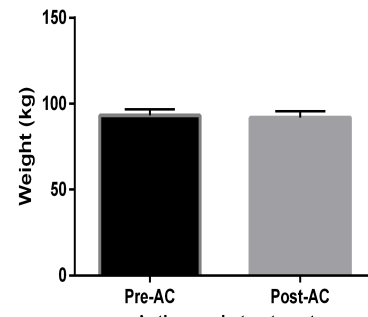

Anthocyanin treatment

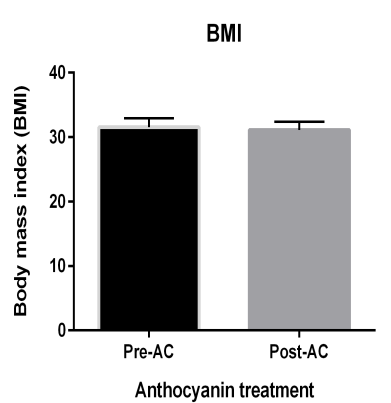

Anthocyanin treatment

Figure 1: Anthropometric measurements show both body weight and body mass index. Data presented as mean \pm SEM.

\section{Blood pressure measurements}

Blood pressure measurement showed no change in patients with T2DM after consumption of AC, as illustrated by figure 2 .
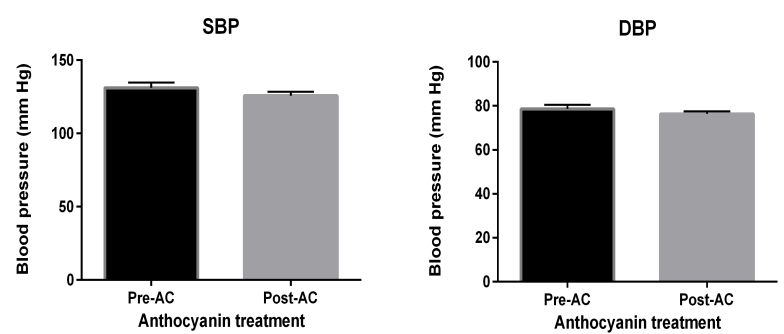

Figure 2: Blood pressure measurements. were collected before and after ingestion of AC. Data presented as mean \pm SEM.

\section{Platelet aggregation study}

Mean platelet aggregation was measured by platelet aggregometry. Three different agonists were used, including ADP, collagen, and arachidonic acid (AA). Figure 3 showed three diagrams and each bar chart displays mean platelet aggregation in the presence of a corresponding agonist. This study detected a significant reduction of mean platelet aggregation in the presence of the ADP $(p=0.0198)$ and collagen $(p=0.0158)$ agonists respectively, but there is no effect on AA-stimulated platelet aggregation.

\section{Immunophenotyping of platelet activation}

The flow-cytometry assay demonstrated the cell surface expression of P-selectin (CD62p), which is an activation marker of platelets. The analysis of platelet activation markers showed no effect of AC on platelet activation in patients with T2DM, as shown in figure 4.

\section{Biochemical analysis}

As shown by table 4 . The results showed a significant reduction in total cholesterol in response to AC consumption. However, there were trends of insignificantly reduced blood levels of LDL and triglycerides.

Table 4: Biochemical analysis of some parameters under the effect of AC.

\begin{tabular}{|l|c|c|c|c|}
\hline $\begin{array}{c}\text { Biochemistry } \\
\text { Assay }\end{array}$ & $\begin{array}{c}\text { Pre-AC } \\
\text { Mean } \pm \text { SEM }\end{array}$ & $\begin{array}{c}\text { Post-AC } \\
\text { Mean } \pm \text { SEM }\end{array}$ & P value & $\begin{array}{c}\text { R e f e r e n c e } \\
\text { range }\end{array}$ \\
\hline TC $(\mathrm{mM})$ & $5.1 \pm 0.29$ & $4.6 \pm 0.32$ & $0.0051^{*}$ & $<5.5$ \\
\hline HDL $(\mathrm{mM})$ & $0.94 \pm 0.04$ & $0.89 \pm 0.04$ & 0.1010 & $>1.1$ \\
\hline TG $(\mathrm{mM})$ & $2.4 \pm 0.27$ & $1.9 \pm 0.22$ & 0.1015 & $<2.6$ \\
\hline FBG $(\mathrm{mM})$ & $6.00 \pm 0.35$ & $5.9 \pm 0.39$ & 0.8211 & $4.1-6.0$ \\
\hline UA & $312 \pm 22$ & $307 \pm 19$ & 0.7418 & $202-416$ \\
\hline LDL $(\mathrm{mM})$ & $3.4 \pm 0.23$ & $3.1 \pm 0.27$ & 0.1237 & $2.0-3.4$ \\
\hline
\end{tabular}

Values are represented as mean \pm SEM. A significant reduction in total cholestero levels was observed post AC supplementation. Abbreviations: AC, anthocyanin; TC, total cholesterol; HDL, high-density lipoprotein; TG, triglycerides; FBG, fasting blood glucose; UA, uric acid; LDL, low-density lipoprotein. ${ }^{\star} \mathrm{P}<0.05$.

\section{Coagulation analysis}

AC supplementation did not influence clotting times for prothrombin time (PT) and activated partial thromboplastin time (aPTT) coagulation assays. Fibrinogen and D-Dimer also showed no change under AC effect observed post AC supplementation, as shown in figure 5.

\section{Cellular adhesion molecules}

Analysis of vascular cell adhesion molecule (VCAM-1) and intercellular adhesion molecule (ICAM-1) shows no effect of AC, as shown in figure 6.

\section{Proinflammatory analytes}

As illustrated by figure 7, both biomarkers, including high sensitive C-reactive protein (CRP-HS) and IL-8, demonstrate no change in their serum levels under the effect of AC. 

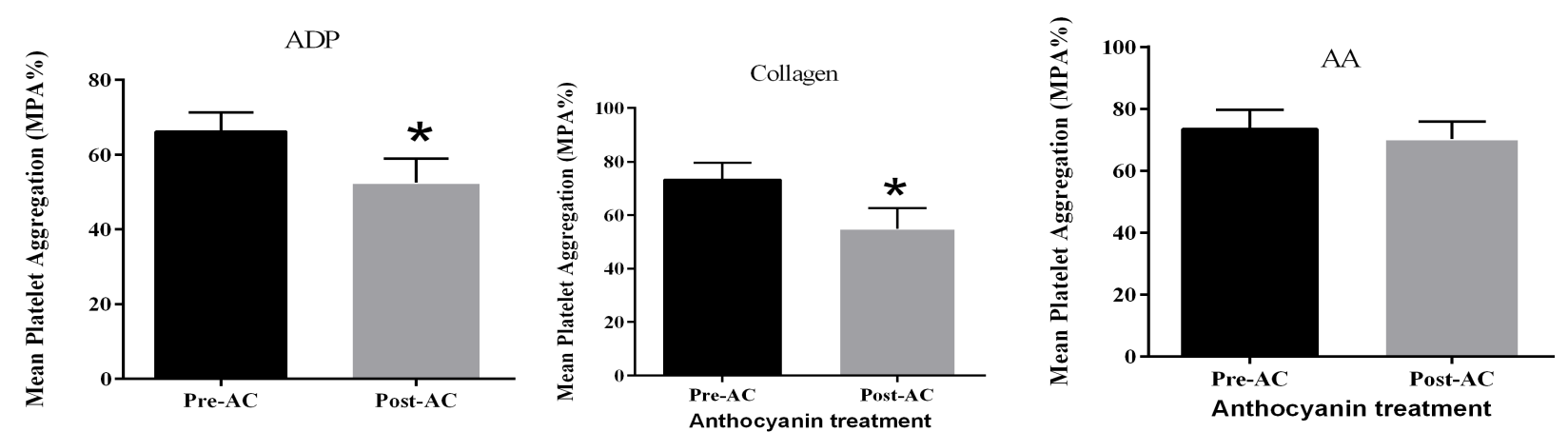

Figure 3: Platelet aggregation study. stimulated by different agonists including ADP, Collagen, and AA. Data presented as mean \pm SEM.as mean \pm SEM.

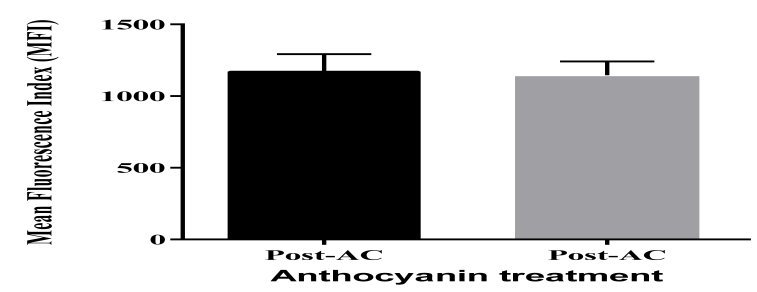

Figure 4: Immunophenotyping of platelet activation. Flow-cytometry analysis of expression of surface marker of P-selectin in activated platelets. Data presented as mean \pm SEM.
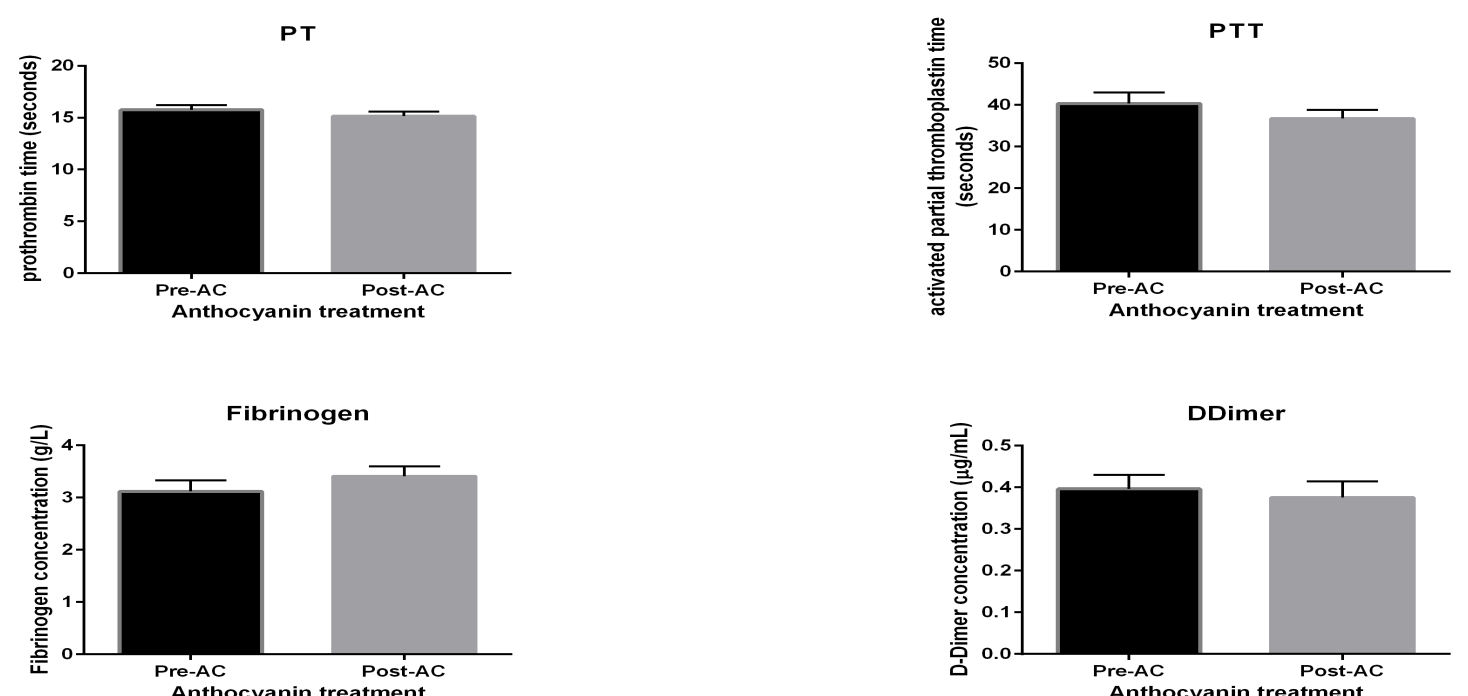

Figure 5: coagulation analysis. Coagulation assay of samples of T2DM participants before and after consumption of AC. Data presented as mean \pm SEM. Abbreviations:
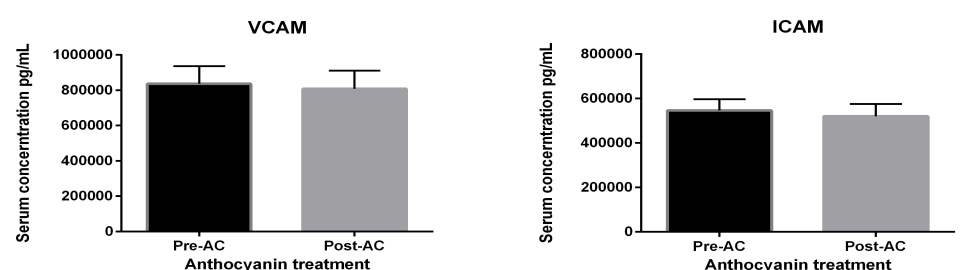

Figure 6: cellular adhesion molecules. Soluble adhesion markers under AC effects in patients with diabetes: Abbreviations: vascular-cellular adhesion molecule (VCAM-1) and intercellular adhesion molecule (ICAM-1). The above figures show serum levels of adhesion molecules under $320 \mathrm{mg} /$ day AC consumption for four weeks intervention. There was no change in their blood levels post-intervention trial. Data presented as mean \pm SEM. 

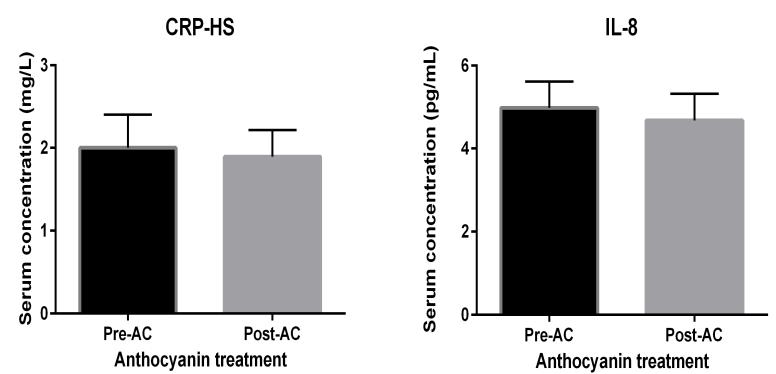

Figure 7: proinflammatory analytes. Proinflammatory molecules under AC effects in patients with diabetes: Abbreviations: high sensitivity $\mathrm{C}$ reactive protein (HSCRP) and interleukin-8 (IL-8). Data presented as mean \pm SEM

\section{Discussion}

The study aim was to investigate the anti-platelet and antithrombotic effects of AC in patients with diabetes. Anthropometric measurements and blood pressure values were measured before and after the treatment period. The aggregation and activation of platelets were assessed by platelet aggregometry and flow cytometry. Coagulation analysis and proinflammatory and adhesion markers were conducted. This study also investigated haematological indices and biochemical blood tests.

Platelet aggregability increases in T2DM due to multifactorial process. Intrinsic platelet factors and high platelet sensitivity to different agonists enhance platelet aggregation [30]. In the present study, three exogenous agonists, including ADP, collagen and AA, were used to stimulate platelet aggregation. These agonists represent three different mechanistic pathways of platelet activation. The P2Y G protein-coupled receptors located on the platelet surface are responsible for ADP induced platelet activation and aggregation that will result in platelet shape change, granule release and thromboxane A2 production. ADP mechanistically has initiated platelet activation by binding to the $\mathrm{P} 2 \mathrm{Y} 1$ and $\mathrm{P} 2 \mathrm{Y} 12$ receptors to induce internal calcium mobilisation and degranulation. Previously, anti-thrombotic drugs such as clopidogrel have been used to blunt the expression of $\mathrm{P} 2 \mathrm{Y} 1$ and $\mathrm{P} 2 \mathrm{Y} 12$ receptors and inhibit platelet activation and aggregation. The results from this study have demonstrated that $\mathrm{AC}$ supplementation for 28 days can significantly inhibit the ADP-induced platelet aggregation in patients with T2DM. Hence, suggesting that AC extract from bilberries and blackcurrant may exert its anti-platelet effect by blunting the P2Y1 and P2Y12 receptor-mediated platelet activation and aggregation similar to anti-platelet drug clopidogrel.

The observed inhibitory effect of AC supplementation agrees with the finding of several other studies that showed an AC rich diet could inhibit ADP induced platelet aggregation. In a recent study by Thomson K et.al., 28 day AC supplementation inhibited ADP induced platelet aggregation by $29 \%$ in the sedentary population [27]. Also, the results from this study have shown that AC supplementation for four weeks can significantly inhibit the collagen-induced platelet aggregation. Anthocyanins are part of other antioxidants family of flavonoids which has an antagonising effect on collagen-stimulated platelet aggregation by mitigating the oxidative burst which is initiated after binding platelets with collagen [31]. There are two primary receptors for collagen on platelets, namely glycoprotein six (GPVI) and the integrin $\alpha 2 \beta 1$, which both have a crucial role in the process of haemostasis [32]. Collagen receptors on binding, initiate intracellular signalling pathway and consequently trigger platelet activation and aggregation [32]. The data of this study is parallel with Aviram and colleagues. They detected an $11 \%$ reduction of platelet aggregation due to the inhibitory effects of phenolic compounds, including AC, in a dietary intervention study investigating collagen-stimulated platelet aggregation (32).

This study showed no change in AA-stimulated platelet aggregation. This effect is probably due to improved production of thromboxane-A2 as platelets produce more TXA2 in response to different stimuli in $\mathrm{T} 2 \mathrm{DM}[30,33]$. However, several other in vivo studies have demonstrated that other sources of $\mathrm{AC}$ such as strawberries and Queen Garnet plum can inhibit AA-induced platelet aggregation [29, 34].

P-selectin is an adhesion molecule present on the membrane of a-granules expressed to the surface only upon platelet activation by the process of exocytosis [35]. It is believed that the desensitisation of platelet activation-dependent superficial receptors by AC interferes with signal transduction, thus reducing P-selectin release of $\alpha$-granule contents following platelet activation [36]. Flavonoids, including AC, may reduce platelet production of superoxide anion, and increase platelet nitric oxide production [37], which inhibit platelet adhesion and activation. The inhibitory effect of $\mathrm{AC}$ on the expression of P-selectin on activated platelets can reduce platelet hyperactivity in response to various stressors such as oxidative stress and shear stress that lead to thrombotic events and CVD $[28,38]$.

However, there was no impact of AC on reducing expression of P-selectin in patients with T2DM in the current study. Diminished effect of $\mathrm{AC}$ on lowering platelet activity as shown by the expression of CD62P in this study may be due to increased expression of CD62P and upregulation P-selectin receptors on platelets in patients with T2DM $[30,39,40]$. Also, the limited action of AC in T2DM might be due to increased oxidative stress, particularly in uncontrolled patients [30]. Oxidative stress eliminates endothelial nitric oxide synthase activity and lowers the formation of nitric oxide, and augments intracellular signalling of platelet receptors [30]. This action might increase the burden on the current dose and time of AC (320 mg/day) consumption to alleviate the expression of platelet activation marker of CD62p in the current trial.

Other studies have also investigated the effect of AC in reducing P-selectin expression on platelets; however, the source of AC and its concentration, the sample population, or the agonist used for platelet activation were different. Song et al. discovered an inhibitory effect of AC on the level of P-selection in hypercholesteremic patients [41]. Yao et al. found a significant inhibitory effect of cyanidin-3-glucoside on the expression of CD62P [42]. Yang et al. detected a considerable reduction of P-selection in dyslipidaemic rats supplemented with AC extract from black rice [43]. Andreas et al. found an inhibitory effect 
of AC on the expression of P-selectin of resting and activated platelets [36]. This effect is not consistent with findings of others regarding the impact of $\mathrm{AC}$ on the expression of CD62P on the surface of Platelets $[27,28,37]$. However, the sample population in the current trial is different from populations of those studies. The duration of the intervention was short in this study. More extended intervention in future studies may provide more positive results.

There is no effect of AC on levels of adhesion molecules in this study. However, other studies have shown that $\mathrm{AC}$ reduces vascular cell adhesion molecules $[44,45]$. Cellular adhesion biomarkers have a crucial impact on the pathophysiology of ischemic events and might be used as predictors of high thrombotic risk [46]. It has been shown that increased oxidative stress upregulates adhesion molecules expression [46].

The current study demonstrates no impact of AC on serum levels of pro-inflammatory markers, including HS-CRP and IL-8. Few other studies have also measured the effect of AC in lowering pro-inflammatory biomarkers, but the sample population, type of inflammatory markers, and the source of AC were different. It has been shown by other studies which implemented diverse sample populations and doses and duration of AC treatment, that AC has demonstrated more powerful impact on lowering inflammatory markers [47-52].

Supplementation of AC showed a significant reduction of total cholesterol but no other analytes of the lipid profile nor other biochemical markers in the current trial. It has been hypothesized that AC may improve lipid profile by lowering of HMG-CoA reductase gene activation. It is thus reducing the synthesis of cholesterol in different ways. First, inhibit cholesteryl ester transfer protein (CEPT) which reduces circulating concentrations of LDL [53]. Second, it lowers apolipoprotein B and apolipoprotein C-III-lipoprotein levels in the blood $[24,53]$.

Additionally, anthocyanin facilitates the excretion of cholesterol through faeces [54]. LDL and triglycerides and fasting blood glucose in patients with T2DM. The inhibitory effect of antioxidants on biochemical parameters has been shown by other researchers [55-57]. The link between dyslipidaemia and inflammation may be attributed by the fact that elevated serum cholesterol is associated with a higher level of pro-inflammatory cytokines. Hence, the protective effect of anthocyanin could also be dual $[58,59]$. It has been shown that AC improves glucose tolerance and reduce hyperglycaemia by improving beta-cell function and increase insulin secretion [60].

According to the current study data, there is no impact of AC on different parameters of haematological indices. Few other studies have investigated the effect of $\mathrm{AC}$ on variable haematological indices, but they used various sources and concentrations of AC on different sample populations, too [61-63]. Piekarska et al. conducted an animal study to show the impact of $\mathrm{AC}$ on increasing different blood cell counts, including RBC, HGB, MCH, MCHC, RDW, and WBC [61]. The most significant strength of this clinical trial is that, to our knowledge, the current clinical trial is one of the few studies that have demonstrated the benefits of AC supplementation in individuals with T2DM. However, compliance with consuming AC capsules and changes to the participant's diet are self-reported by the participants, which are one of the limitations for the current study.

\section{Conclusion}

Anthocyanin (AC)-rich food has been defined to reduce thrombotic susceptibility by attenuating aggregation pathways of platelets potentially. Although many epidemiological studies have shown the effect of anthocyanin-rich food in reducing platelet hyperactivity, those dietary intervention studies have not demonstrated the direct biological action of AC components on the platelet function and activity. Additionally, the bioavailability of AC changes prominently because of other food constituents. Those elements involve micronutrient, macronutrients, and other antioxidants and exist in the ingested foods, altering the absorptive and antioxidant capacities of AC. However, in this study, the effect of AC metabolites has not been identified, and this might be one of the limitations of detecting the direct impact of AC. This study shows that AC applied an inhibitory effect on platelet aggregation, which ADP and collagen have stimulated in patients with T2DM. There was a significant reduction in the blood level of cholesterol under the impact of AC. In summary, AC can potentially alleviate thrombotic risks and probably lessen the risk of cardiovascular events in patients with T2DM. Moreover, further studies are warranted looking at each mechanistic pathway involved in platelet activity.

\section{Acknowledgment and conflict of interest}

The corresponding author acknowledges the Iraqi government/ Ministry of higher education and scientific research scholarship program and the Australian government, research training program scholarship. The authors declare no conflicts of interest statement.

\section{References}

1. Davi G, Falco A (2005) Oxidant stress, inflammation and atherogenesis. Lupus 14(9):760-4. [crossref]

2. Abdul-Ghani M, DeFronzo RA, Del Prato S, Chilton R, Singh R, Ryder RE, et al. (2017) Cardiovascular disease and type 2 diabetes: has the dawn of a new era arrived? Diabetes Care 40(7):813-20. [crossref]

3. Freedman JE (2008) Oxidative stress and platelets. Arteriosclerosis, thrombosis, and vascular biology 28(3):s11-s6. [crossref]

4. Wellen KE, Hotamisligil GS (2005) Inflammation, stress, and diabetes. The Journal of clinical investigation 115(5):1111-9. [crossref]

5. Hassan RH, de Sousa ACP, Mahfouz R, Hainault I, Blachnio-Zabielska A, Bourron O, et al. (2016) Sustained action of ceramide on the insulin signaling pathway in muscle cells implication of the double-stranded RNA-activated protein kinase. Journal of Biological Chemistry 291(6):3019-29. [crossref]

6. Boullier A, Bird DA, CHANG MK, Dennis EA, Friedman P, GILLOTTE-TAYLOR K, et al. (2001) Scavenger receptors, oxidized LDL, and atherosclerosis. Annals of the New York Academy of Sciences 947(1):214-23. [crossref]

7. Santhakumar AB, Bulmer AC, Singh I (2014) A review of the mechanisms and effectiveness of dietary polyphenols in reducing oxidative stress and thrombotic risk. Journal of Human Nutrition and Dietetics 27(1):1-21. [crossref] 
8. McFadyen JD, Schaff M, Peter K (2018) Current and future antiplatelet therapies: emphasis on preserving haemostasis. Nature Reviews Cardiology 15:181. [crossref]

9. Paven E, Dillinger J, Sollier CBD, Vidal-Trecan T, Launay J, Dautry R, et al. (2018) Determinants of aspirin loss of efficacy in type 2 diabetic patients. Archives of Cardiovascular Diseases Supplements 10(1):114-5.

10. Vernstrøm L, Funck KL, Grove EL, Laugesen E, Baier JM, Hvas A-M, et al. (2018) Antiplatelet effect of aspirin during $24 \mathrm{~h}$ in patients with type 2 diabetes without cardiovascular disease. Thrombosis research 161:1-6. [crossref]

11. Angiolillo DJ, Fernandez-Ortiz A, Bernardo E, Ramírez C, Sabaté M, JimenezQuevedo P, et al. (2005) Platelet function profiles in patients with type 2 diabetes and coronary artery disease on combined aspirin and clopidogrel treatment. Diabetes 54(8):2430-5. [crossref]

12. Lepäntalo A, Virtanen KS, Reséndiz JC, Mikkelsson J, Viiri LE, Karhunen PJ, et al. (2009) Antiplatelet effect of clopidogrel in patients with aspirin therapy undergoing percutaneous coronary interventions-Limited inhibition of the P2Y 12 receptor. Thrombosis research 124(2):193-8. [crossref]

13. Vitseva O, Varghese S, Chakrabarti S, Folts JD, Freedman JE (2005) Grape seed and skin extracts inhibit platelet function and release of reactive oxygen intermediates. Journal of cardiovascular pharmacology 46(4):445-51. [crossref]

14. Erlund I, Koli R, Alfthan G, Marniemi J, Puukka P, Mustonen P, et al. (2008) Favorable effects of berry consumption on platelet function, blood pressure, and HDL cholesterol. The American journal of clinical nutrition 87(2):323-31. [crossref]

15. Kuehl KS, Perrier ET, Elliot DL, Chesnutt JC (2010) Efficacy of tart cherry juice in reducing muscle pain during running: a randomized controlled trial. Journal of the International Society of Sports Nutrition 7(1):1. [crossref]

16. Hung H-C, Joshipura KJ, Jiang R, Hu FB, Hunter D, Smith-Warner SA, et al. (2004) Fruit and vegetable intake and risk of major chronic disease. Journal of the National Cancer Institute 96(21):1577-84. [crossref]

17. Genkinger JM, Platz EA, Hoffman SC, Comstock GW, Helzlsouer KJ (2004) Fruit, vegetable, and antioxidant intake and all-cause, cancer, and cardiovascular disease mortality in a community-dwelling population in Washington County, Maryland. American journal of epidemiology 160(12):1223-33. [crossref]

18. Wallace TC (2011) Anthocyanins in Cardiovascular Disease. Advances in Nutrition: An International Review Journal 2(1):1-7. [crossref]

19. Holt RR, Actis-Goretta L, Momma TY, Keen CL (2006) Dietary flavanols and platelet reactivity. Journal of cardiovascular pharmacology 47:S187-S96. [crossref]

20. Benavente-Garcia O, Castillo J, Lorente J, Ortuno A, Del Rio J (2000) Antioxidant activity of phenolics extracted from Olea europaea L. leaves. Food Chemistry 68(4):45762 .

21. Aviram M, Fuhrman B (2002) Wine flavonoids protect against LDL oxidation and atherosclerosis. Annals of the New York Academy of Sciences 957(1):146-61. [crossref]

22. Borochov-Neori H, Judeinstein S, Greenberg A, Fuhrman B, Attias J, Volkova N, et al. (2008) Phenolic antioxidants and antiatherogenic effects of Marula (Sclerocarrya birrea Subsp. caffra) fruit juice in healthy humans. Journal of agricultural and food chemistry 56(21):9884-91. [crossref]

23. Martín S, González-Burgos E, Carretero ME, Gómez-Serranillos MP (2013) Protective effects of Merlot red wine extract and its major polyphenols in PC12 cells under oxidative stress conditions. Journal of food science 78(1):H112-H8. [crossref]

24. Li D, Zhang Y, Liu Y, Sun R, Xia M (2015) Purified Anthocyanin Supplementation Reduces Dyslipidemia, Enhances Antioxidant Capacity, and Prevents Insulin Resistance in Diabetic Patients-3. The Journal of nutrition 145(4):742-8. [crossref]

25. Qin Y, Xia M, Ma J, Hao Y, Liu J, Mou H, et al. (2009) Anthocyanin supplementation improves serum LDL-and HDL-cholesterol concentrations associated with the inhibition of cholesteryl ester transfer protein in dyslipidemic subjects. The American journal of clinical nutrition 90(3):485-92. [crossref]

26. Zhu Y, Xia M, Yang Y, Liu F, Li Z, Hao Y, et al. (2011) Purified anthocyanin supplementation improves endothelial function via NO-cGMP activation in hypercholesterolemic individuals. Clinical chemistry 57(11):1524-33. [crossref]
27. Thompson K, Hosking H, Pederick W, Singh I, Santhakumar AB (2017) The effect of anthocyanin supplementation in modulating platelet function in sedentary population: a randomised, double-blind, placebo-controlled, cross-over trial. The British journal of nutrition 118(5):368-74. [crossref]

28. Santhakumar AB, Kundur AR, Fanning K, Netzel M, Stanley R, Singh I (2015) Consumption of anthocyanin-rich Queen Garnet plum juice reduces platelet activation related thrombogenesis in healthy volunteers. Journal of Functional Foods 12(0):11-22.

29. Santhakumar AB, Kundur A, Sabapathy S, Stanley R, Singh I (2015) The potential of anthocyanin-rich Queen Garnet plum juice supplementation in alleviating thrombotic risk under induced oxidative stress conditions. 747-57 p.

30. Gaiz A, Mosawy S, Colson N, Singh I (2017) Thrombotic and cardiovascular risks in type two diabetes; Role of platelet hyperactivity. Biomedicine \& pharmacotherapy 94:679-86. [crossref]

31. Faggio C, Sureda A, Morabito S, Sanches-Silva A, Mocan A, Nabavi SF, et al. (2017) Flavonoids and platelet aggregation: A brief review. European Journal of Pharmacology 807:91-101. [crossref]

32. Pollitt AY, Hughes CE, Watson SP (2013) Chapter 11 - GPVI and CLEC-2. In: Michelson AD, editor. Platelets (Third Edition). Academic Press p. 215-31.

33. Willecke F, Nagareddy PR, Murphy AJ (2017) Mechanisms of Platelet Activation in Diabetes Mellitus. Platelets, Haemostasis and Inflammation: Springer p. 137-52.

34. Santhakumar AB, Kundur A, Fanning K, Netzel M, Stanley R, Singh I (2015) Consumption of anthocyanin-rich Queen Garnet plum juice reduces platelet activation related thrombogenesis in healthy volunteers. 11-22 p.

35. Krga I, Vidovic N, Milenkovic D, Konic-Ristic A, Stojanovic F, Morand C, et al. (2018) Effects of anthocyanins and their gut metabolites on adenosine diphosphate-induced platelet activation and their aggregation with monocytes and neutrophils. Archives of Biochemistry and Biophysics 645:34-41.

36. Guerrero JA, Navarro-Nuñez L, Lozano ML, Martínez C, Vicente V, Gibbins JM, et al. (2007) Flavonoids inhibit the platelet TxA2 signalling pathway and antagonize TxA2 receptors (TP) in platelets and smooth muscle cells. British journal of clinical pharmacology 64(2):133-44. [crossref]

37. Vita JA (2005) Polyphenols and cardiovascular disease: effects on endothelial and platelet function-. The American journal of clinical nutrition 81(1):292S-7S. [crossref]

38. Semenov AV, Kagan-Ponomarev MY, Ruda MY, Komarov AL, Panchenko EP, Chazova IE, et al. (2000) Soluble P-selectin - A marker of platelet activation and vessel wall injury. Increase of soluble P-selectin in the blood plasma of patients with myocardial infarction, massive atherosclerosis and primary pulmonary hypertension. Terapevticheskii arkhiv 72(4):15-20. [crossref]

39. Eibl N, Krugluger W, Streit G, Schrattbauer K, Hopmeier P, Schernthaner G (2004) Improved metabolic control decreases platelet activation markers in patients with type-2 diabetes. European journal of clinical investigation 34(3):205-9.

40. Colwell JA, Nesto RW (2003) The platelet in diabetes: focus on prevention of ischemic events. Diabetes Care 26(7):2181-8. [crossref]

41. Song F, Zhu Y, Shi Z, Tian J, Deng X, Ren J, et al. (2014) Plant food anthocyanins inhibit platelet granule secretion in hypercholesterolaemia: Involving the signalling pathway of PI3K-Akt. Thrombosis and haemostasis 112(5):981-91.

42. Yao Y, Chen Y, Adili R, McKeown T, Chen P, Zhu G, et al. (2017) Plant-based Food Cyanidin-3-Glucoside Modulates Human Platelet Glycoprotein VI Signaling and Inhibits Platelet Activation and Thrombus Formation. The Journal of nutrition 147(10):1917-25. [crossref]

43. Yang Y, Andrews MC, Hu Y, Wang D, Qin Y, Zhu Y, et al. (2011) Anthocyanin Extract from Black Rice Significantly Ameliorates Platelet Hyperactivity and Hypertriglyceridemia in Dyslipidemic Rats Induced by High Fat Diets. Journal of Agricultural and Food Chemistry 59(12):6759-64.

44. Jayaprakasam B, Vareed SK, Olson LK, Nair MG (2005) Insulin secretion by bioactive anthocyanins and anthocyanidins present in fruits. J Agric Food Chem 53(1):28-31. [crossref] 
45. Gaiz A, Mosawy S, BusAdmin G, Colson N, Singh I (2018) Potential of Anthocyanin to Prevent Cardiovascular Disease in Diabetes. Alternative Therapies in Health \& Medicine 24(3). [crossref]

46. Robson R, Kundur AR, Singh I (2018) Oxidative stress biomarkers in type 2 diabetes mellitus for assessment of cardiovascular disease risk. Diabetes \& Metabolic Syndrome: Clinical Research \& Reviews 12(3):455-62. [crossref]

47. Del Bo' C, Roursgaard M, Porrini M, Loft S, Møller P, Riso P (2016) Different effects of anthocyanins and phenolic acids from wild blueberry (Vaccinium angustifolium) on monocytes adhesion to endothelial cells in a TNF- $\alpha$ stimulated proinflammatory environment. Molecular nutrition \& food research 60(11):2355-66. [crossref]

48. Carvalho FB, Gutierres JM, Bohnert C, Zago AM, Abdalla FH, Vieira JM, et al. (2015) Anthocyanins suppress the secretion of proinflammatory mediators and oxidative stress, and restore ion pump activities in demyelination. The Journal of nutritional biochemistry 26(4):378-90.

49. Kim S-M, Min H-K, Baek S-Y, Woo J-W, Park J-S, Cho M-L, et al. (2015) Anthocyanin extracted from black soybean seed coats prevents autoimmune arthritis by suppressing the development of Th17 cells and synthesis of proinflammatory cytokines by such cells, via inhibition of NF-kB (THER3P. 972). Am Assoc Immnol. [crossref]

50. Chen KC, Yang CH, Li TT, Zouboulis CC, Huang YC (2019) Suppression of Propionibacterium acnes-stimulated proinflammatory cytokines by Chinese bayberry extracts and its active constituent myricetin in human sebocytes in vitro. Phytotherapy Research 33(4):1104-13. [crossref]

51. Knobloch TJ, Uhrig LK, Pearl DK, Casto BC, Warner BM, Clinton SK, et al. (2016) Suppression of proinflammatory and prosurvival biomarkers in oral cancer patients consuming a black raspberry phytochemical-rich troche. Cancer Prevention Research 9(2):159-71. [crossref]

52. Kim S, Hong J, Jeon R, Kim H-S (2016) Adzuki bean ameliorates hepatic lipogenesis and proinflammatory mediator expression in mice fed a high-cholesterol and highfat diet to induce nonalcoholic fatty liver disease. Nutrition Research 36(1):90-100. [crossref]

53. Qin Y, Xia M, Ma J, Hao Y, Liu J, Mou H, et al. (2009) Anthocyanin supplementation improves serum LDL-and HDL-cholesterol concentrations associated with the inhibition of cholesteryl ester transfer protein in dyslipidemic subjects-. The American journal of clinical nutrition 90(3):485-92. [crossref]
54. Souza MOd, Silva LS, Magalhães CLdB, Figueiredo BBd, Costa DC, Silva ME, et al. (2012) The hypocholesterolemic activity of açaí (Euterpe oleracea Mart.) is mediated by the enhanced expression of the ATP-binding cassette, subfamily G transporters 5 and 8 and low-density lipoprotein receptor genes in the rat. [crossref]

55. Shah K, Shah P (2018) Effect of Anthocyanin Supplementations on Lipid Profile and Inflammatory Markers: A Systematic Review and Meta-Analysis of Randomized Controlled Trials. Cholesterol 2018:12. [crossref]

56. de Pascual-Teresa S, Moreno DA, García-Viguera C (2010) Flavanols and anthocyanins in cardiovascular health: a review of current evidence. International journal of molecular sciences 11(4):1679-703. [crossref]

57. Zhu Y, Ling W, Guo H, Song F, Ye Q, Zou T, et al. (2013) Anti-inflammatory effect of purified dietary anthocyanin in adults with hypercholesterolemia: a randomized controlled trial. Nutrition, Metabolism and Cardiovascular Diseases 23(9):843-9. [crossref]

58. Stokes KY (2006) Microvascular responses to hypercholesterolemia: the interactions between innate and adaptive immune responses. Antioxidants \& redox signaling 8(78):1141-51. [crossref]

59. Busnelli M, Froio A, Bacci ML, Giunti M, Cerrito MG, Giovannoni R, et al. (2009) Pathogenetic role of hypercholesterolemia in a novel preclinical model of vascular injury in pigs. Atherosclerosis 207(2):384-90.

60. Gowd V, Jia Z, Chen W (2017) Anthocyanins as promising molecules and dietary bioactive components against diabetes - A review of recent advances. Trends in Food Science \& Technology 68:1-13.

61. Piekarska J, Szczypka M, Kucharska AZ, Gorczykowski M (2018) Effects of iridoidanthocyanin extract of Cornus mas L. on hematological parameters, population and proliferation of lymphocytes during experimental infection of mice with Trichinella spiralis. Experimental Parasitology 188:58-64.

62. Al Groom RM, Al-Kubaisy K (2016) Anthocyanin-rich red dye of Hibiscus sabdariffa L. Calyx Modulates $\mathrm{CdCl} 2$-induced hypochromic microcytic anaemia and oxidative stress in rat red blood cells. J Environ 5(1):13-8.

63. Maslachah L, Sugihartuti R, Wahyuni RS (2019) Hematologic changes and splenic index on malaria mice models given Syzygium cumini extract as an adjuvant therapy. Veterinary world 12(1):106. [crossref]

\section{Citation:}

Almottesembellah Gaiz, Sapha Shibeeb, Avinash Reddy Kundur, Natalie Colson, Anahita Aboonabi, Josif Vidimce, and Indu Singh, et al. (2021) Anthocyanin Effects in Reducing Platelet Hyperactivity and Thrombotic Risk in Type 2 Diabetes. Endocrinol Diabetes Metab J Volume 5(1): 1-9. 